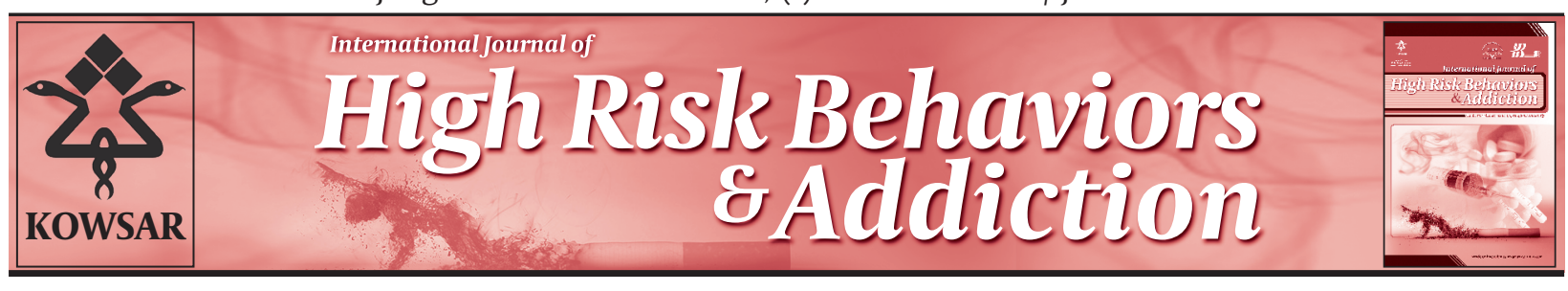

\title{
Evaluation of Nutritional Status in Drug Users Referred to the Center of Drug Dependency Treatment in Zahedan
}

\author{
Mansour Karajibani ${ }^{*}$, Farzaneh Montazerifar ${ }^{1}$, Mansour Shakiba ${ }^{2}$ \\ ${ }^{1}$ Department of Nutrition and Zahedan Health Promotion Research Center, School of Medicine, Zahedan University of Medical Sciences, Zahedan, IR Iran \\ ${ }^{2}$ Department of Psychiatry, Zahedan University of Medical Sciences, Zahedan, IR Iran
}

\begin{tabular}{l}
\hline A R T I C L E I N F O \\
\hline Article type: \\
Original Article \\
\hline Article history: \\
Received: 25 Jul 2011 \\
Revised: 25 Sep 2011 \\
Accepted: 05 Oct 2011 \\
\hline
\end{tabular}

Keywords:

Drug Users

Food Intake Regulation

Nutritional Status

\begin{abstract}
A B S T R A C T
Background: Drug addiction is a lifestyle disease. An assessment of the nutritional state of addicts is often done in parallel to their medical treatment.

Objectives: The aim of the present study was to investigate the nutritional status of drug addicts.

Patients and Methods: This study was conducted among 54 drug addicts ( 47 men and 7 women) who sought detoxification treatment at the Central Drug Addiction Treatment Hospital in center of drug dependency treatment (Baharan Hospital) in Zahedan, Iran. Age, body weight, and height were measured. Body mass index (BMI) was calculated by dividing body weight $(\mathrm{kg})$ by the square of the height $\left(\mathrm{m}^{2}\right)$. The percentile of the BMI indicator dictated the nutritional status in the subjects. The amount of food consumed was determined according to the number of servings consumed in the different food groups and was compared to the recommended allowances given by the Food Guide Pyramid.

Results: The mean age, body weight, height, and BMI were $34.4 \pm 9.7$ years, $63.1 \pm 10.1 \mathrm{~kg}$, $171.1 \pm 11.6 \mathrm{~cm}$, and $21.8 \pm 4.4 \mathrm{~kg} / \mathrm{m}^{2}$, respectively. According to the percentile status of the BMIs, the results showed that $35.2 \%, 20.4 \%, 37 \%$, and $7.4 \%$ of subjects were wasting, at risk of wasting, normal, or overweight, respectively. When their intake was compared to the Food Guide Pyramid, $72.2 \%$ of the subjects showed a deficiency in the bread and cereal group, $67.2 \%$ in vegetables, $57.4 \%$ in fruits, $40.7 \%$ in milk and dairy products, and $24.1 \%$ in the meat group.

Conclusions: The present study revealed different degrees of malnutrition among drug addicts with multiple deficiencies in both macro- and micronutrients.
\end{abstract}

Copyright $\odot 2012$ Kowsar Corp. All rights reserved.

- Implication for health policy/practice/research/medical education:

Since there was not any information about nutritional status in the drug addicts in this area; The aim of this study was to investigate the nutritional status in them. It seems the results of this study can help in treatment and health promotion of this affected group

Please cite this paper as:

Karajibani M, Montazerifar F, Shakiba M. Evaluation of Nutritional Status in Drug Addicts Referred to the Center of Drug Dependency Treatment in Zahedan. Int J High Risk Behav Addict. 2012; 1(1):18-21. DOI: 10.5812/ijhrba.4176

\section{Background}

Drug addiction is a lifestyle disease that can lead to social and public health problems (1). Many studies on addicts have demonstrated nutritional deficiencies, in-

\footnotetext{
${ }^{*}$ Corresponding author: Mansour Karajibani, Department of Nutrition, Zahedan University of Medical Sciences, Zahedan, IR Iran. Tel: + 98-5413414552-

7, Fax:+98-5413414552, E-mail:mkarajibani@gmail.com

DOI:10.5812/ijhrba.4176

Copyright $\odot 2012$ Kowsar Corp. All rights reserved.
}

cluding weight loss and changes in dietary patterns (2). Apparently, drugs do not affect energy intake directly, but probably affect the nutritional quality of the meals an addict chooses (3). The protein calorie malnutrition of many drug addicts is linked to factors such as female gender, intensity of the addiction, anorexia, poor diet, and an alteration of the addict's social and familial links (3). Nutritional deficiencies can severely and permanently affect different organ functions; in particular, energy, 
protein, vitamin, and mineral deficiencies can cause several nutritional disorders. Many drug addicts suffer from calorie and protein malnutrition $(3,4)$. The prevalence of malnutrition in drug addicts and the influence of their drug habit and lifestyle on their nutritional indices have been investigated (5).

Many studies have shown a relationship between drug addiction and education, income, and body mass index (BMI) (2). Most addicts suffer from nutritional and metabolic disorders. It is necessary to consider a proper diet based on individual characteristics that lead to different physiological changes. Addicts need good health, inspiration, support, and proper nourishment. The aim of the present study was to investigate the nutritional status in drug addicts referred to a center for the treatment of drug dependence.

\section{Objectives}

The aim of the present study was to investigate the nutritional status in drug addicts.

\section{Patients and Methods}

\subsection{Subjects}

In this descriptive, cross-sectional study, 54 drug addicts (47 men and 7 women) were enrolled during the period of January to April 2007. All persons referred to the Center of Drug Dependency Treatment of Zahedan were informed of the study and asked for their consent to participate. They were multi-drug users of substances such as heroin, opiates, crack, and morphine, and they sought detoxification in the Central Drug Addiction Treatment Hospital (C.D.A.T) of Baharan, Zahedan, Iran. All were seen by a specialist, who described the study they would enter. The hospital specializes in detoxification therapy and provides facilities for drug addicts. Age, body weight, and barefoot height were measured using digital scales (Seca, Germany) and a non-stretch tape fixed to a flat vertical wall. BMI was calculated by dividing body weight $(\mathrm{kg})$ by the square of the height $\left(\mathrm{m}^{2}\right)$, and its percentile position in the BMI indicator was determined.

\subsection{Nutritional Assessment}

The cutoff points used to determine nutritional status in the subjects were the following: $\mathrm{BMI} \leq 5^{\text {th }}$ percentile, wasting; $5^{\text {th }}$ to $<15^{\text {th }}$, risk of wasting; $15^{\text {th }}$ to $<85^{\text {th }}$, normal weight; $>85^{\text {th }}$ to $\leq 95^{\text {th }}$, overweight; and $>95^{\text {th }}$, obese $(6$, $7)$. The subjects responded to the nutritional questionnaire based on the Pyramid Food Guidance System. They recalled the different food groups from which they consumed at 2 different time points. During the course of the study, a nutritionist and educated expert regularly advised the subjects. The food questionnaire, which provided information about food consumption, was administered by a trained nutritionist.

Before putting the data into a computer, standard refer- ence tables were used to convert household portions to grams of consumed food. The Food Guide Pyramid offers a method for determining appropriate patterns for daily food choices based on the 5 major food groups from which recommended consumptions are selected: bread and cereals, 6-11 exchanges/day; fruits, 2-4 exchanges/ day; vegetables, 3-5 exchanges/day; milk and dairy products, 2-3 exchanges/day; meat, egg, dried beans, nuts, and substitutes, 2-3 exchanges/day; and small amounts of fats, oils, and sweets (8).

For each case, the food intake was determined according to the number of servings reported in each food group. These amounts were then compared to the recommended allowances from the Food Guide Pyramid.

\subsection{Statistical Analysis}

Results are expressed as Mean \pm SD. The statistical analysis was performed using SPSS 11.5 software, with ethical points for the subjects duly observed.

\section{Results}

Of the 54 drug addicts, $87 \%$ were men and 13\% women, with ages ranging from 19 to 67 years. Mean age, body

\begin{tabular}{lll}
\hline \multicolumn{2}{l}{ Table 1. Characteristics of the Drug Addicts } \\
\hline & Mean \pm SD & Min-Max \\
Age, y & $34.4 \pm 9.7$ & $19-67$ \\
\hline Body weight, kg & $63.1 \pm 10.1$ & $46-58$ \\
Height, cm & $171.1 \pm 11.6$ & $139-189$ \\
BMI $^{\mathrm{a}}, \mathrm{kg} / \mathrm{m}^{2}$ & $21.8 \pm 4.4$ & $16.2-26.1$ \\
\hline
\end{tabular}

a Abbreviation: BMI, Body mass indext

Table 2. Nutritional Status of Drug Addicts Based on Percentile of Body Mass Index

\begin{tabular}{ll}
\hline & No. $(\%)$ \\
\hline Wasting & $19(40.4)$ \\
Men & $0(0)$ \\
Women, & $19(35.2)$ \\
Total & \\
Risk of wasting & $10(21.3)$ \\
Men & $1(14.3)$ \\
Women & $11(20.4)$ \\
Total & \\
Normal & $16(34.1)$ \\
Men & $4(57.1)$ \\
Women & $20(37)$ \\
Total & \\
Overweight & \\
Men & $2(4.2)$ \\
Women & $2(28.6)$ \\
Total & $4(7.4)$ \\
Total & \\
Men & $47(87 \%)$ \\
Women & $7(13 \%)$ \\
Total & $54(100)$ \\
\hline
\end{tabular}




\begin{tabular}{lccc}
\hline Table 3. Comparison of Food Intake With Food Guide Pyramid & & \\
\hline & Serving & No. $(\%)$ & Recommended Allowance \\
\hline Bread and cereals & $<6$ exchange & $39(72.2)$ & 6-11 exchange \\
& $>6$ exchange & $15(27.8)$ & 3-5 exchange \\
Vegetables & $<3$ exchange & $44(67.2)$ & \\
& $>3$ exchange & $31(32.8)$ & \\
Fruits & $<2$ exchange & $31(57.4)$ & 2-3 exchange \\
& $>2$ exchange & $33(42.6)$ & \\
Milk and dairy products & $<2$ exchange & $22(40.7)$ & 2-3 exchange \\
& $>2$ exchange & $32(59.3)$ & \\
Meat, egg, and substitutes & $<2$ exchange & $13(24.1)$ & $41(75.9)$ \\
\end{tabular}

weight, height, and BMI were $34.4 \pm 9.7$ years, $63.1 \pm 10.1 \mathrm{~kg}$, $171.1 \pm 11.6 \mathrm{~cm}$, and $21.8 \pm 4.4 \mathrm{~kg} / \mathrm{m}^{2}$, respectively (Table 1).

The BMI results showed that $40.4 \%$ men and $0 \%$ women were wasting; $21.3 \%$ men and $14.3 \%$ women were at risk of wasting; $34.1 \%$ men and $57.1 \%$ women were of normal weight; and $4.2 \%$ men and $28.6 \%$ women were overweight (Table 2).

The results also revealed the following mean consumptions in the different food groups: bread, rice, and cereals, 4.8 exchanges/day; vegetables, 0.8 exchanges/day; fruits, 1.3 exchanges/day; milk and dairy products, 1.9 exchanges/day; meat, eggs, dried beans, nuts, and substitutes, 1.9 exchanges/day. According to the standard Food Guide Pyramid, 72.2\% of the subjects were deficient in the bread and cereal group; $67.2 \%$, in vegetables; $57.4 \%$, in fruits; $40.7 \%$, in milk and dairy products; and $24.1 \%$, in meat (Table 3).

\section{Discussion}

The results of this study demonstrated malnutrition of different degrees: mild, moderate, and severe. As indicated by the BMIs, $65 \%$ of the subjects were wasting. Nazrul Islam et al. have reported that $60-74 \%$ of drug addicts had below normal BMI and showed clinical signs of nutritional deficiency (1). Many addicts have caloric and protein malnutrition related to their poor intake of food and liquids $(1,3)$. Data from the Third National Health and Nutrition Examination Survey (NHANES III), 1988-1994, showed marijuana users to have BMIs slightly lower, and they also consumed less fruit and cheese (9).

The comparison of food intake with the Food Guide Pyramid demonstrated both macro- and micronutrient deficiencies. Alves et al. have suggested a relationship between nutritional status and food consumption of ad- dicts in methadone maintenance treatment (2). Those findings agree with the study by Smith et al. that noted low intakes of fruits and vegetables in drug users (10). The failure to meet healthy daily minimum intake levels of grains, fruits, and vegetables may be due to the fact that drug addicts focus only on satiety when they have feelings of scorn about their next meal (2). The results are supported by another study which showed low intakes of fruits and vegetables in drug users (11). Because the patients in this study are undergoing treatment and take drugs regularly, they need to take vitamins and minerals to improve their health. Some of the opiate drugs reduce the absorption of such vitamins as A, C, and E. Deficiencies in antioxidant vitamins in drug addicts have previously been reported (11). A number of following components in foods have been found to have antioxidant properties; they have specific activities and usually work synergistically to improve the antioxidant ability of the body (12). The findings here showed the ratio of intake of cereals and rice to be too low for producing energy. Although, the calorie intake was not determined in this study, lack of energy intake can cause deficiency in such macro- and micronutrients such as proteins, essential fatty acids, vitamins, and minerals. Santolaria-Feranoez et al. found the mean caloric intake to be $978 \pm 89 \mathrm{kcal} /$ day in females and $1256 \pm 64 \mathrm{kcal} /$ day in males. Acute organic pathology aggravates the poor nutritional status of drug addicts (3). In tandem with the deficient intake from the cereal group, a deficient consumption of food from the milk and dairy group and the meat groups was observed. These findings demonstrate the poor pattern of food consumption in these patients. In drug addicts, who often have amino acid deficiency, the conversion process from protein to amino acids can slow or stop. Therefore, a deficiency of protein sources, especially animal protein 
can lead to malnutrition. Balanced meals high in complex carbohydrate, protein, and fiber and low in fat, with adequate calories for a healthy body weight, are recommended (8). An assessment of nutritional status includes any combination of biochemical and body composition measurements, dietary intake assessment, and metabolic studies (13). In conclusion, the present study revealed that drug addicts had different degrees of malnutrition and multiple nutrient deficiencies. Therefore, in parallel to clinical management, programs to promote an adequate nutritional status and to modify lifestyles, with supporting nutritional and educational programs, are recommended.

\section{Acknowledgments}

The authors would like to thank the experts and emergency section staff at the Central Drug Addiction Treatment Hospital (C.D.A.T) of Baharan Zahedan, Iran for their kind cooperation, as well as the patients and healthy subjects who willingly participated in the study.

\section{Financial Disclosure}

The authors have no financial conflicts of interest.

\section{Funding/Support}

The authors have not received any support.

\section{References}

1. Nazrul Islam SK, Jahangir Hossain K, Ahmed A, Ahsan M. Nutritional status of drug addicts undergoing detoxification: prevalence of malnutrition and influence of illicit drugs and lifestyle.
Brit J Nutr. 2002;88(5):507-13.

2. Alves D, Costa AF, Custódio D, Natário L, Ferro-Lebres V, Andrade F. Housing and employment situation, body mass index and dietary habits of heroin addicts in methadone maintenance treatment. Association for the Application of Neuroscientific Knowledge to Social Aims, AU-CNS. 2011;13(1):1592-638.

3. Santolaria-Fernandez FJ, Gomez-Sirvent JL, Gonzalez-Reimers CE, Batista-Lopez JN, Jorge-Hernandez JA, Rodriguez-Moreno F, et al. Nutritional assessment of drug addicts. Drug Dep. 1995;38(1):11-8.

4. Morabia A, Fabre J, Chee E, Zeger S, Orsat E, Robert A. Diet and opiate addiction: a quantitative assessment of the diet of noninstitutionalized opiate addicts. Brit J Addic. 1989;84(2):173-80.

5. Varela P, Marcos A, Ripoll S, Santacruz I, Requejo AM. Effects of human immunodeficiency virus infection and detoxification time on anthropometric measurements and dietary intake of male drug addicts. Am J Clinic Nutr. 1997;66(2):509S-14S.

6. Swallen KC, Reither EN, Haas SA, Meier AM. Overweight, obesity, and health-related quality of life among adolescents: the National Longitudinal Study of Adolescent Health. Pediatrics. 2005;115(2):340-7.

7. Switzerland G. Obesity: preventing and managing the global epidemic. Report of a WHO consultation. World Health Organization technical report series. 2000;894:i-xii, 1-253.

8. Mahan LK E-sS. Krause's food, nutrition, and diet therapy. 12 ed. the University of Michigan: Elsevier, Sounders; 2004.

9. Smit E, Crespo CJ. Dietary intake and nutritional status of US adult marijuana users: results from the Third National Health and Nutrition Examination Survey. Pub Health Nutr. 2001;4(3):781-6.

10. Smit E, Graham NM, Tang A, Flynn C, Solomon L, Vlahov D. Dietary intake of community-based HIV-1 seropositive and seronegative injecting drug users. J Nutrition. 1996;12(7-8):496-501.

11. Nazrul Islam SK, Jahangir Hossain K, Ahsan M. Serum vitamin E, $C$ and $A$ status of the drug addicts undergoing detoxification: influence of drug habit, sexual practice and lifestyle factors. Euro J Clinic Nutr. 2001 Nov;55(11):1022-7.

12. Bagchi K, Puri S. Free radicals and antioxidants in health and disease. East Mediterr Health J.1998;4(350):60.

13. Smit E, Tang A. Nutritional assessment in intravenous drug users with HIV/AIDS. J Acquir Immune Defic Syndr;25 (Suppl 1):S62-9. 